\title{
The management of schizophrenia: focus on extended-release quetiapine fumarate
}

This article was published in the following Dove Press journal:

Neuropsychiatric Disease and Treatment

20 September 2011

Number of times this article has been viewed

\section{Joseph Peuskens}

Universitair Psychiatrisch Centrum KU Leuven, Campus St Jozef Kortenberg, Kortenberg, Belgium
Correspondence: Joseph Peuskens Universitair Psychiatrisch Centrum KU Leuven, Campus St Jozef Kortenberg, Leuvensesteenweg 517, B-3070,

Kortenberg, Belgium

Tel +32 27580503

Fax +32 27595380

Email joseph.peuskens@uc-kortenberg.be

\begin{abstract}
Effective management of schizophrenia remains a significant clinical challenge. While antipsychotic medications have proven efficacy in this disease, there remains an opportunity to further improve symptom control and long-term relapse prevention. Also, a number of factors, including tolerability and complex dosing regimens, can result in nonadherence to medication. Quetiapine is an atypical antipsychotic with proven efficacy and an established tolerability profile in schizophrenia. The once-daily extended-release formulation (quetiapine XR) offers a simplified dosing regimen and titration schedule. Short-term clinical studies have shown that quetiapine XR (400-800 mg/d) is efficacious in the acute treatment of schizophrenia, while a long-term study has shown that quetiapine XR was significantly more effective than placebo at preventing relapse. Furthermore, an investigation in which stable patients switched from the immediate-release formulation (quetiapine IR) to quetiapine XR showed that quetiapine XR is generally well tolerated and has no loss of efficacy compared with quetiapine IR. In patients who experienced insufficient efficacy or poor tolerability on their previous antipsychotic, switching to quetiapine XR significantly improved efficacy compared with the previous treatment. In conclusion, quetiapine $\mathrm{XR}$ is an effective and generally well tolerated treatment for schizophrenia. Furthermore, once-daily dosing may improve patient adherence, which may impact positively on patient outcomes.
\end{abstract}

Keywords: adherence, atypical antipsychotics, adverse events

\section{Introduction}

Schizophrenia is a debilitating and isolating disease imposing a significant burden on the lives of those affected, and its effective, and particularly long-term, management remains a significant clinical challenge. Enduring symptomatic improvement is required to improve and maintain quality of life and day-to-day functioning, and to achieve reasonable patient expectations of daily living. To achieve these goals, successful pharmacological treatment should be individualized and should provide a good balance between efficacy and tolerability. ${ }^{1}$

Whilst the responsibility of optimizing treatment lies in the hands of the physician, the extent of any clinical benefit is severely compromised if the patient does not take medication as prescribed. For patients with schizophrenia, nonadherence or partial adherence to medication is common, with almost half of patients estimated to be taking their medication as prescribed less than $75 \%$ of the time. ${ }^{2}$ Furthermore, the number of patients adherent to medication has been shown to decrease proportionally over time. ${ }^{3}$ Partial adherence to antipsychotic medication can lead to significant 
problems when trying to evaluate medication efficacy, optimize dose, and determine any requirement for concomitant medication. ${ }^{4}$

Moreover, partial adherence or nonadherence has serious clinical consequences including worsening of psychotic symptoms, increased (self-) aggression, suboptimal longterm outcome, and perhaps most significantly, increased risk of relapse and hospitalization. ${ }^{5-8}$ Schizophrenic relapse has been shown to be associated with poor prognosis and increased health care costs. ${ }^{9,10}$

In addition to the clinical impact, nonadherence is associated with a considerable financial burden. A retrospective review of Medicaid 2001-2003 data describing patients with schizophrenia suggested that elimination of nonadherence leading to hospitalization (which accounted for $36.6 \%$ of acute care inpatient admissions) could result in a $12 \%$ reduction in acute care admissions and a $13 \%$ reduction in the number of inpatient treatment days. Altogether this was estimated to realize savings of approximately US\$106 million in the United States alone. ${ }^{11}$

A wide variety of factors influence adherence to medication, including patient- (eg, age, attitude toward illness and treatment), illness- (eg, patient insight and comorbidity), physician- (eg, provision of information and the physicianpatient relationship), and treatment-related issues. ${ }^{2,12}$ In an investigation into the reasons for poor adherence, 153 patients with schizophrenia were asked to identify factors they considered to be barriers to medication adherence. The mean number of barriers identified per patient was 1.8; the barriers identified are presented in Figure $1 .{ }^{13}$ The most commonly reported barriers included social stigma associated with psychiatric illness, adverse events (AEs), and memory problems.

Separately, it has been shown that patients with a negative attitude toward treatment, which can be a direct result of poor tolerability, are more likely to be nonadherent to their

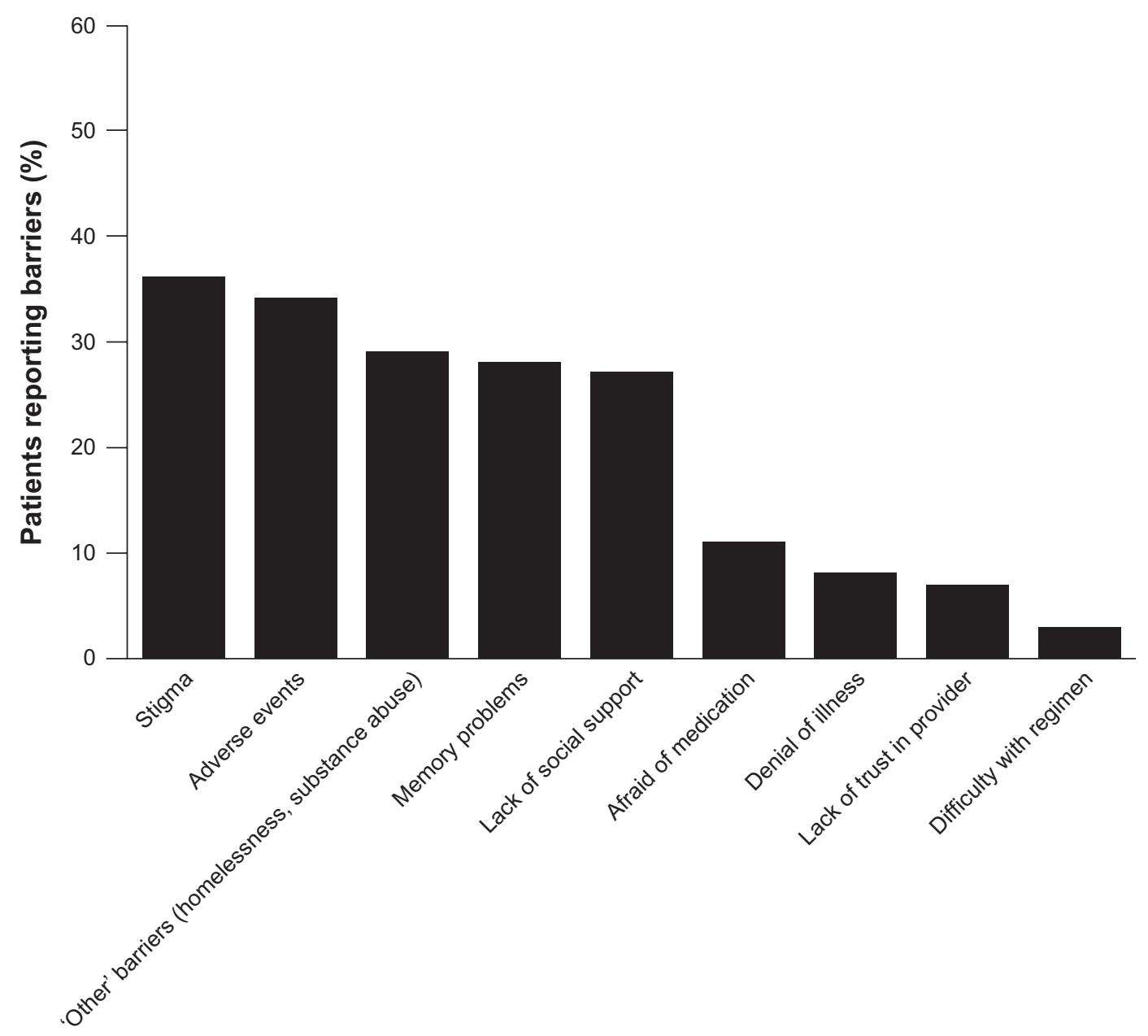

Figure I Reported barriers to medication adherence in patients with schizophrenia.

Hudson TJ, Owen RR, Thrush CR, et al. A pilot study of barriers to medication adherence in schizophrenia. J Clin Psychiatry. 2004;65(2):2II-2I6.'3 Copyright (C) 2004 Physicians Postgraduate Press. Reprinted by permission. 
antipsychotic medication. ${ }^{14}$ Patients with schizophrenia have been demonstrated to have more concern, more negative opinions, and less feeling of necessity than patients with bipolar disorder. ${ }^{2,15}$ A lack of efficacy can also result in patients discontinuing their medication. ${ }^{16-18}$ Also, poor insight, previous nonadherence, substance abuse, shorter illness duration, inadequate aftercare, and a poorer patientphysician relationship have all been shown to be consistently associated with nonadherence, whereas factors including education level, neurocognitive impairment, severity of psychotic symptoms, and the presence of mood symptoms were not consistently associated with lack of adherence. ${ }^{2}$

Atypical antipsychotics are currently considered to be first-line treatments for schizophrenia. ${ }^{19,20}$ A key advantage of the atypical antipsychotics over the conventional antipsychotics is that, as a class, they are better tolerated, in particular with regard to their reduced propensity for extrapyramidal symptoms (EPSs). ${ }^{21}$ However, atypical antipsychotics have been associated with weight gain and metabolic AEs, with the incidence of these events varying according to the drug studied. ${ }^{22,23}$

Immediate-release quetiapine fumarate (quetiapine IR) is a well established, effective, atypical antipsychotic treatment for patients with schizophrenia, having shown efficacy across a broad range of symptoms (positive, negative, cognitive, and affective) ${ }^{24-27}$ The recommended initial dose of quetiapine IR is $25 \mathrm{mg}$ twice daily, with increases in total daily dose of 25-50 mg divided into two or three daily doses on days 2 and 3 , as tolerated, to a daily dose range of $300-400 \mathrm{mg}$, given in two or three doses, by day 4 . When dose adjustment is required, increases or decreases of 25-50 mg divided twice daily are recommended. ${ }^{28}$ It has also been reported that a more rapid titration can provide safe and effective treatment. ${ }^{24}$ Extended-release quetiapine fumarate (quetiapine XR) is a once-daily formulation, developed to provide patients and physicians with a more convenient dosing regimen and a simpler dose initiation so patients can reach the recommended therapeutic dose range $(400-800 \mathrm{mg} / \mathrm{d})$ by day $2-3$ of treatment. ${ }^{29}$

Quetiapine XR is effective and generally well tolerated in patients with schizophrenia or bipolar disorder, ${ }^{30,31}$ and is currently approved for the treatment of schizophrenia, acute manic and mixed episodes associated with bipolar I disorder, and acute treatment of depressive episodes associated with bipolar disorder in the United States ${ }^{32}$ and several other countries around the world. Beyond acute treatment, quetiapine XR is approved for relapse prevention in patients with stable schizophrenia. ${ }^{33}$ Quetiapine $\mathrm{XR}$ is also approved for maintenance treatment of bipolar I disorder as adjunctive therapy to lithium or divalproex in the United States $^{32}$ and for recurrence prevention in bipolar disorder as monotherapy in the European Union. ${ }^{34}$ Several studies have demonstrated the efficacy of quetiapine XR in major depressive disorder (MDD) ${ }^{35-39}$ and generalized anxiety disorder, ${ }^{40-43}$ and quetiapine XR has recently been approved in the United States and the European Union as adjunctive treatment to antidepressants in adults with MDD. ${ }^{44,45}$

This review will examine the pharmacokinetics, pharmacology, efficacy, and tolerability of quetiapine XR in patients with schizophrenia and will discuss the potential clinical benefits of this new formulation in the treatment of schizophrenia.

\section{Pharmacokinetic overview of quetiapine $\mathbf{X R}$}

The quetiapine XR formulation is based on gel matrix technology using a soluble polymer to control the release of quetiapine fumarate from the tablet. When hypromellose comes into contact with water, the polymer swells and forms a gelatinous layer around the tablet that helps control the release of quetiapine from the tablet core. Quetiapine release is predominantly erosion controlled and occurs gradually, rather than the rapid release into the blood stream seen with the IR formulation. Consequently, quetiapine XR provides comparable bioavailability, compared with the existing IR formulation. Moreover, the time to reach peak plasma concentration $\left(\mathrm{C}_{\max }\right)$ is prolonged, and plasma levels are sustained at higher levels for a longer period of time. As a result of these properties, the quetiapine XR formulation allows less frequent dosing to maintain therapeutic drug concentrations. ${ }^{46}$

\section{Pharmacokinetic profile}

Quetiapine XR and IR each have a linear pharmacokinetic profile and a half-life of approximately 7 hours when administered at doses within the recommended therapeutic range. ${ }^{47,48}$ An open-label, randomized, crossover study in patients with schizophrenia, schizoaffective disorder, or bipolar disorder reported equivalent areas under the 24-hour quetiapine plasma concentration curve with the XR and IR formulations. ${ }^{46}$ Once-daily dosing of quetiapine XR $300 \mathrm{mg}$ gave rise to mean $\mathrm{C}_{\text {max }}$ approximately $13 \%$ lower than those observed with twice-daily dosing of quetiapine IR $150 \mathrm{mg}$ and took longer to reach $\mathrm{C}_{\max }$ (5 hours versus 2 hours) (Figure 2). ${ }^{46}$ Comparison of once-daily dosing of the XR and IR formulations (both $300 \mathrm{mg}$ ) found a geometric mean ratio 


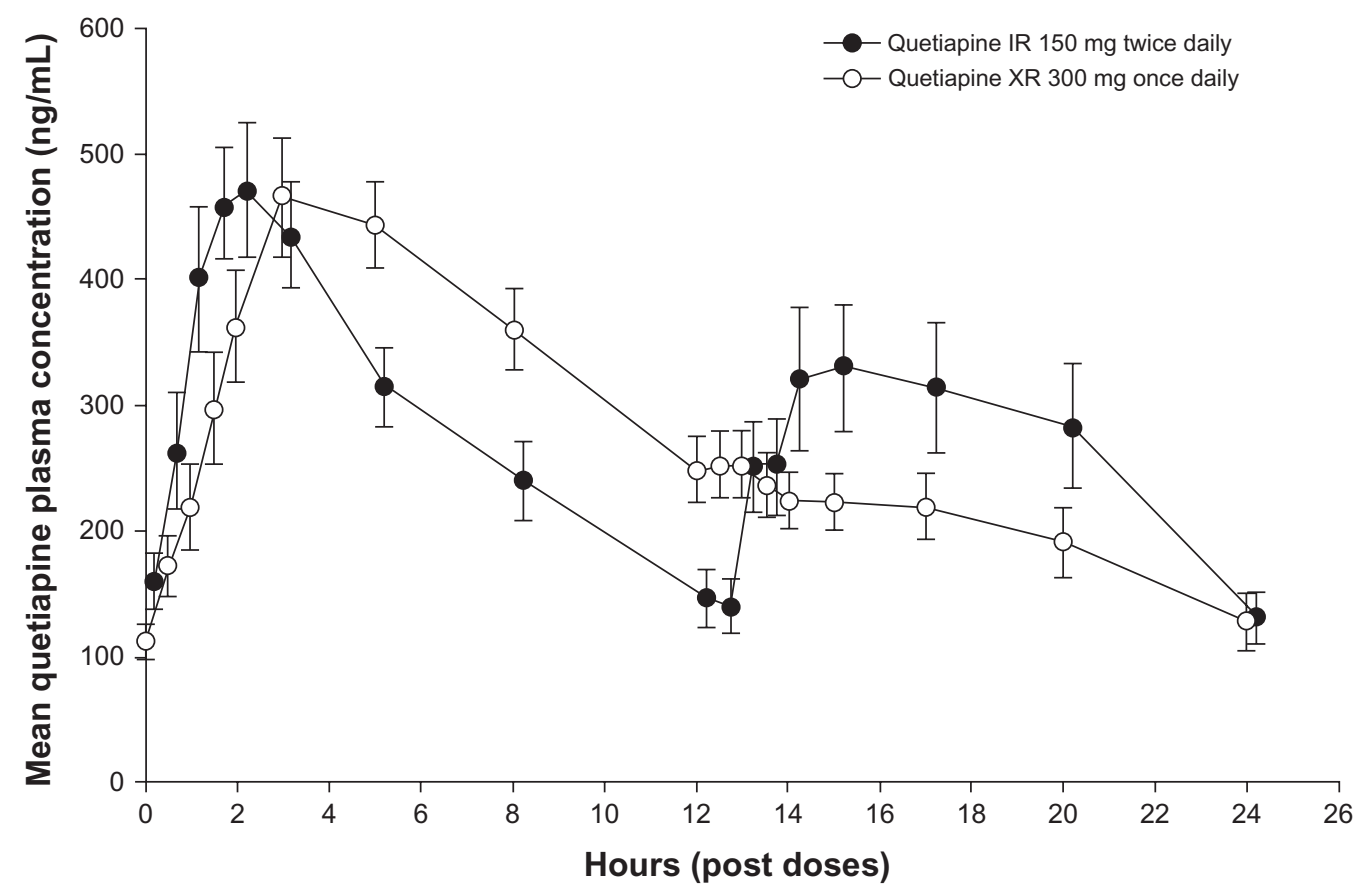

Figure 2 Mean plasma quetiapine concentrations (and standard errors of the mean) measured over a 24-hour dosing interval for quetiapine IR and quetiapine XR. Reproduced with permission. ${ }^{46}$ Figueroa C, Brecher M, Hamer-Maansson JE, Winter H. Pharmacokinetic profiles of extended release quetiapine fumarate compared with quetiapine immediate release. Prog Neuropsychopharmacol Biol Psychiatry. 2009;33(2): I99-204.

Abbreviations: IR, immediate release; $X R$, extended release.

for $\mathrm{C}_{\max }$ of 0.55 (90\% confidence interval [CI] 0.49-0.60) and for the area under the plasma concentration-time curve from time 0 to 11 hours post-dose of 0.89 (90\% CI 0.82-0.96); time to $\mathrm{C}_{\max }\left(\mathrm{T}_{\max }\right)$ was 5 hours and 2 hours, respectively. ${ }^{49}$ The extended $\mathrm{T}_{\max }$ with the XR formulation means that evening dosing of quetiapine XR ensures lower plasma levels of quetiapine during the day. It is recommended that quetiapine XR not be taken with food because despite intake of a light meal (300 calories, no fat) having no significant effect on quetiapine XR steady-state pharmacokinetics,${ }^{50}$ consumption of a high-fat meal increases quetiapine XR bioavailability. ${ }^{29}$ The recommendation that once-daily quetiapine XR be administered in the evening should minimize the clinical relevance of any impact of food consumption on quetiapine XR bioavailability.

\section{Mechanism of action of quetiapine}

Both quetiapine and its relatively recently characterized major active human metabolite, norquetiapine (N-desalkylquetiapine), have moderate affinity for dopamine $\mathrm{D}_{2}$ receptors, and are potent antagonists of serotonin 5-hydroxytryptamine type $2 \mathrm{~A}\left(5-\mathrm{HT}_{2 \mathrm{~A}}\right)$ receptors. ${ }^{51}$ Occupancy of $\mathrm{D}_{2}$ receptors is thought to be the primary route by which antipsychotic agents mediate their effect; however, it is also considered to be the main mechanism responsible for inducing EPSs. The reduced incidence of EPSs with atypical antipsychotics, including quetiapine, compared with conventional antipsychotics is believed to be a result of their rapid dissociation from $\mathrm{D}_{2}$ receptors ${ }^{52}$ and higher affinity for $5-\mathrm{HT}_{2 \mathrm{~A}}$ receptors. ${ }^{53}$ Positron emission tomography (PET) studies have shown low to moderate $\mathrm{D}_{2}$ occupancy by quetiapine throughout the therapeutic dose range for schizophrenia, $400-800 \mathrm{mg} / \mathrm{d}$, due to its rapid dissociation from the receptor. ${ }^{54,55}$

The established pharmacological profile of quetiapine does not adequately explain the antidepressant and moodstabilizing properties of quetiapine IR and quetiapine XR observed in clinical trials. Whilst questions remain, the combined effects of quetiapine and norquetiapine may provide an explanation for the observed clinical profile. For example, norquetiapine has a moderate affinity for the $5-\mathrm{HT}_{2 \mathrm{C}}$ receptor (antagonist) and is a partial agonist for the $5-\mathrm{HT}_{1 \mathrm{H}}$ receptor, which together with antagonism of the $5-\mathrm{HT}_{2 \mathrm{~A}}$ receptor, may be associated with cognitive and mood enhancing/stabilizing properties. ${ }^{56}$

In addition to its affinity for $\mathrm{D}_{2}$ and $5-\mathrm{HT}_{2}$ receptors, norquetiapine is also a potent inhibitor of the norepinephrine transporter (NET). PET imaging in nonhuman primates has demonstrated quetiapine and norquetiapine occupancy at $\mathrm{D}_{2}$, $5-\mathrm{HT}_{2 \mathrm{~A}}$, and norquetiapine occupancy at the NET at clinically relevant plasma levels. ${ }^{57}$ The clinical relevance of these findings has been supported by PET studies demonstrating NET occupancy by norquetiapine in humans. Also, quetiapine and 
norquetiapine bind to the $5-\mathrm{HT}_{1 \mathrm{~A}}$ and $5-\mathrm{HT}_{1 \mathrm{C}}$ receptors with a moderate to high affinity, which is similar to established antidepressants. ${ }^{58}$ The receptor-binding profile of quetiapine and norquetiapine may explain its efficacy demonstrated across a number of different psychiatric disorders. ${ }^{58}$

A further PET study, which compared the $\mathrm{D}_{2}$ receptor binding at peak and trough plasma concentration in patients with schizophrenia, found that quetiapine IR (dosed twice daily) and quetiapine XR (dosed once daily) 300, 600, and $800 \mathrm{mg} / \mathrm{d}$ demonstrated comparable central $\mathrm{D}_{2}$ receptor occupancy for both formulations. ${ }^{59}$ PET scans in a study in healthy volunteers showed that $\mathrm{D}_{2}$ occupancy at maximum quetiapine plasma concentration was consistently lower in individuals treated with quetiapine XR $300 \mathrm{mg}$ once daily compared with those receiving quetiapine IR $300 \mathrm{mg}$ once daily (32\% versus $49 \%) .{ }^{55}$ These combined pharmacological properties of quetiapine have not been described for any other psychotropic drug.

Norquetiapine and quetiapine have also shown high affinity for the histaminergic $\mathrm{H}_{1}$ receptor, and moderate affinity for the adrenergic receptor $\alpha_{1 \mathrm{~B}}$. While quetiapine has low affinity for muscarinic receptors, norquetiapine acts as an antagonist at the muscarinic receptors $M_{1}, M_{3}$, and $M_{5}$. These mechanisms may contribute to the side-effect profile of quetiapine. ${ }^{58}$

Additionally, in common with other atypical antipsychotics, ${ }^{60}$ evidence from animal models suggests that quetiapine may have neuroprotective effects, mediated through its modulation of the expression of neurotrophic factors including brain-derived neurotrophic factor. ${ }^{61,62}$

\section{Clinical efficacy studies}

Several clinical trials have been conducted to evaluate the efficacy of quetiapine XR in patients with schizophrenia over both the short and long term. In addition, the feasibility of switching from quetiapine IR or other antipsychotic medication to quetiapine $\mathrm{XR}$ has been investigated (Table 1)..$^{31,63-67}$

\section{Acute trials}

To date, three 6-week trials to investigate the efficacy and tolerability of quetiapine XR and quetiapine IR versus placebo for the treatment of acute schizophrenia have been conducted. In all trials, male or female patients were aged 18-65 years, and with a Diagnostic and Statistical Manual of Mental Disorders, 4th Edition (DSM-IV) diagnosis of schizophrenia. Patients were excluded if they had a DSM-IV diagnosis of any condition other than schizophrenia.
Quetiapine XR has demonstrated efficacy in the treatment of acute schizophrenia in a randomized, double-blind, placebo-controlled trial (D1444C00132). ${ }^{64}$ This was an international study conducted in 39 centers in Europe, Asia, and South Africa. Patients $(n=588)$ were randomized to receive fixed-dose quetiapine XR 400, 600, or $800 \mathrm{mg} / \mathrm{d}$ (once daily in the evening), quetiapine IR $400 \mathrm{mg} / \mathrm{d}$ (200 mg twice daily), or dual-matched placebo (ie, patients receiving quetiapine $\mathrm{XR}$ received placebo in the morning and active treatment in the evening). Quetiapine XR was initiated at $300 \mathrm{mg} / \mathrm{d}$ and rapidly titrated, with target doses reached by day 2 (400 and $600 \mathrm{mg}$ ) or day 3 (800 mg) (Table 2). ${ }^{64}$ The primary efficacy endpoint was change from baseline to week 6 in Positive and Negative Syndrome Scale (PANSS) total score. Last observation carried forward analysis of the modified intention-to-treat population showed that compared with placebo the change in PANSS total score was statistically significant for all four active treatments (Figure 3), ${ }^{64}$ with a post-hoc analysis demonstrating a dose response for quetiapine XR. Analysis of several secondary efficacy variables similarly showed a significant improvement with quetiapine XR and quetiapine IR compared with placebo. At week 6, changes from baseline in PANSS positive and general psychopathology subscales and PANSS aggression/ hostility cluster were statistically significant for all quetiapine doses compared with placebo; decreases in the PANSS negative subscale and depression cluster scores were significant for quetiapine XR 600 and $800 \mathrm{mg} / \mathrm{d} .{ }^{64,68}$ Furthermore, both PANSS and Clinical Global Impression-Improvement scale (CGI-I) response rates at week 6 were significantly greater with all active treatments compared with placebo and CGISeverity of Illness (CGI-S) score was statistically significant for quetiapine XR 600 and $800 \mathrm{mg} / \mathrm{d}$ and quetiapine IR versus placebo. ${ }^{64}$

A similarly designed study (D1444C00133; $n=565$ ), conducted in the United States, failed to demonstrate a significant improvement in efficacy for quetiapine XR (400, 600 , or $800 \mathrm{mg} / \mathrm{d})$ or quetiapine IR $(800 \mathrm{mg} / \mathrm{d})$ compared with placebo. ${ }^{67}$ This outcome was in contrast to the results of study D1444C00132, and surprising given the proven efficacy of quetiapine IR in this patient group. There are several possible reasons for the failure of an active treatment to separate from placebo in a clinical study. In this case, two probable causes may be: the lack of requirement for hospitalization and other factors biasing towards the selection of a less acutely ill patient population, and geographic differences from study 132 resulting in key differences between the two study populations. A post-hoc analysis of the primary 
Table I Summary of published efficacy and tolerability studies of quetiapine XR in adult patients with schizophrenia

\begin{tabular}{|c|c|c|c|}
\hline Study identifier & Study design & Study efficacy outcomes & Reference \\
\hline DI444C00I32 & $\begin{array}{l}\text { 6-week, randomized, double-blind, placebo- } \\
\text { controlled study. } \\
\text { Patients were randomized to receive quetiapine XR } \\
400,600 \text {, or } 800 \mathrm{mg} / \mathrm{d} \text {, quetiapine IR } \\
400 \mathrm{mg} / \mathrm{d} \text {, or placebo. }\end{array}$ & $\begin{array}{l}\text { Significant improvements in PANSS total score, } \\
\text { PANSS, and CGI-I response rates with all active } \\
\text { treatments versus placebo. }\end{array}$ & Kahn et $\mathrm{al}^{64}$ \\
\hline DI444C00I33 & $\begin{array}{l}\text { 6-week, randomized, double-blind, } \\
\text { placebo-controlled study. } \\
\text { Patients were randomized to receive quetiapine XR } \\
400,600 \text {, or } 800 \mathrm{mg} / \mathrm{d} \text {, quetiapine IR } 800 \mathrm{mg} / \mathrm{d} \text {, } \\
\text { or placebo. }\end{array}$ & $\begin{array}{l}\text { Greater numeric improvements in PANSS total } \\
\text { score were seen for quetiapine XR (all doses) } \\
\text { and quetiapine IR versus placebo at week 6; the } \\
\text { differences were not statistically significant. } \\
\text { Secondary efficacy endpoint results did not } \\
\text { significantly separate from placebo. } \\
\text { A post-hoc analysis of the primary efficacy } \\
\text { variable (change in PANSS total score at week 6) } \\
\text { revealed that there was a significant separation } \\
\text { from placebo in patients who were markedly ill } \\
\text { at baseline (CGI-S } \geq 5 \text { ) for the quetiapine XR } \\
600 \text { and } 800 \mathrm{mg} / \mathrm{d} \text { groups. }\end{array}$ & Cutler et $\mathrm{al}^{67}$ \\
\hline 5077IL/004I & $\begin{array}{l}\text { 6-week, randomized, double-blind, placebo- } \\
\text { controlled study. } \\
\text { Patients were randomized to receive quetiapine XR } \\
400,600 \text {, or } 800 \mathrm{mg} / \mathrm{d} \text {, quetiapine IR } 300 \text { or } \\
600 \mathrm{mg} / \mathrm{d} \text {, or placebo. }\end{array}$ & $\begin{array}{l}\text { Statistically significant improvement in PANSS } \\
\text { total score versus placebo recorded only for } \\
\text { quetiapine XR } 600 \mathrm{mg} / \mathrm{d} \text {. } \\
\text { Numerical, but not significant, improvements } \\
\text { in other efficacy measures. }\end{array}$ & Lindenmayer et $\mathrm{al}^{65}$ \\
\hline DI444C00004 & $\begin{array}{l}\text { Long-term, randomized, double-blind, placebo- } \\
\text { controlled study. } \\
\text { Patients received quetiapine XR } 400-800 \text { mg/d } \\
\text { (flexible dosing) for I } 6 \text { weeks; clinically stable } \\
\text { patients were randomized to quetiapine XR } \\
400-800 \mathrm{mg} / \mathrm{d} \text { (flexible dosing) or placebo. }\end{array}$ & $\begin{array}{l}\text { Study terminated early because first interim } \\
\text { analysis showed significant difference between } \\
\text { treatment groups. } \\
\text { Quetiapine XR significantly prolonged time } \\
\text { to relapse versus placebo. }\end{array}$ & Peuskens et $\mathrm{al}^{31}$ \\
\hline DI444C00I46 & $\begin{array}{l}\text { 6-week, double-blind, randomized, parallel group, } \\
\text { fixed-dose study with a 4-week run-in period. } \\
\text { Patients received quetiapine IR 400, 600, or } \\
800 \mathrm{mg} / \mathrm{d} \text { during the run-in period; clinically } \\
\text { stable patients were randomized to receive } \\
\text { quetiapine XR or quetiapine IR at the same } \\
\text { daily dose received during run-in. }\end{array}$ & $\begin{array}{l}\text { Efficacy maintained. } \\
\text { For the per-protocol population, quetiapine XR } \\
\text { was noninferior to quetiapine IR in an analysis } \\
\text { of the proportion of patients who discontinued } \\
\text { due to lack of efficacy, or whose PANSS total } \\
\text { score increased by } \geq 20 \% \text { from randomization. }\end{array}$ & Moller et $\mathrm{al}^{66}$ \\
\hline DI444C00I47 & $\begin{array}{l}\text { I2-week, open-label study in patients with } \\
\text { schizophrenia who were experiencing } \\
\text { inadequate efficacy or tolerability with their } \\
\text { ongoing antipsychotic medication. } \\
\text { Patients were switched to quetiapine XR } \\
400-800 \mathrm{mg} / \mathrm{d} \text { (flexible-dosing) during a } \\
\text { 4-day cross-titration period. }\end{array}$ & $\begin{array}{l}\text { Patients switched to quetiapine } X R \text { experienced } \\
\text { a significant clinical benefit (improvements in } \\
\text { CGI-I and PANSS total scores; } P<0.000 \text { I). }\end{array}$ & Ganesan et al ${ }^{63}$ \\
\hline
\end{tabular}

Abbreviations: CGI-I, Clinical Global Impression-Improvement; IR, immediate release; PANSS, Positive and Negative Syndrome Scale; XR, extended release.

efficacy variable (change in PANSS total score at week 6) revealed that there was a significant separation from placebo in patients who were markedly ill at baseline (CGI-S $\geq 5$ ) for the quetiapine XR 600 and $800 \mathrm{mg} / \mathrm{d}$ groups. In contrast, in patients classified as moderately ill at baseline (CGI-S $<5$ ), there was a rapid and sustained placebo response and no active treatment group separated from placebo.

A further 6-week, randomized, double-blind, placebocontrolled trial (5077IL/0041) investigated the efficacy and tolerability of quetiapine XR $(300,600$, or $800 \mathrm{mg} / \mathrm{d})$ and quetiapine IR (300 and $600 \mathrm{mg} / \mathrm{d}$ ), in 532 patients with acute schizophrenia who were hospitalized for at least the first 10 days of the study. Of the active treatments, only quetiapine XR $600 \mathrm{mg} / \mathrm{d}$ demonstrated significant improvements in the primary outcome measure (change in PANSS score from baseline to week 6). ${ }^{65}$ There was no significant improvement in PANSS total score over the duration of the study with quetiapine IR (300 or $600 \mathrm{mg} / \mathrm{d}$ ), a finding that contrasts with the documented efficacy of quetiapine IR in patients with schizophrenia. For the secondary outcome 
Table 2 Dose initiation schedule for quetiapine $X R$

\begin{tabular}{|c|c|c|c|c|c|c|}
\hline Target dose & Day I & Day 2 & Day 3 & Day 4 & Day 5 & Days 6-42 \\
\hline Quetiapine XR 400 mg & $300 \mathrm{mg}$ & $400 \mathrm{mg}$ & $400 \mathrm{mg}$ & $400 \mathrm{mg}$ & $400 \mathrm{mg}$ & $400 \mathrm{mg}$ \\
\hline Quetiapine XR 600 mg & $300 \mathrm{mg}$ & $600 \mathrm{mg}$ & $600 \mathrm{mg}$ & $600 \mathrm{mg}$ & $600 \mathrm{mg}$ & $600 \mathrm{mg}$ \\
\hline Quetiapine XR 800 mg & 300 mg & $600 \mathrm{mg}$ & 800 mg & $800 \mathrm{mg}$ & $800 \mathrm{mg}$ & $800 \mathrm{mg}$ \\
\hline Quetiapine IR 400 mg & $50 \mathrm{mg}$ & $100 \mathrm{mg}$ & $200 \mathrm{mg}$ & $300 \mathrm{mg}$ & $400 \mathrm{mg}$ & $400 \mathrm{mg}$ \\
\hline
\end{tabular}

Abbreviations: IR, immediate release; $X R$, extended release.

measures evaluated, quetiapine XR and quetiapine IR provided a numerical advantage over placebo; however, significance was not achieved.

The author of this study was unable to identify any one factor responsible for the unexpected outcome of the investigation, and a combination of numerous factors including a high attrition rate and short study duration were considered to be contributory. ${ }^{65}$ It should be noted that this study included a slower dose titration with quetiapine XR, with the $600 \mathrm{mg} / \mathrm{d}$ dose not reached until day 5 , and $800 \mathrm{mg} / \mathrm{d}$ not reached until day 8 . It is possible that this may have resulted in a lower plasma concentration of quetiapine towards the beginning of the trial resulting in attenuated efficacy or premature discontinuation due to perceived lack of efficacy.

\section{Switching studies}

With the introduction of any novel antipsychotic, it is important to evaluate the possibility of switching to the drug from other antipsychotic formulations in order to establish whether efficacy is maintained and to confirm that there are no adverse effects on tolerability.

The viability of switching from quetiapine IR to XR has been investigated in a double-blind, double-dummy study (D1444C00146) in outpatients with schizophrenia. ${ }^{66}$ Patients who were clinically stable (CGI-S score $\leq 3$ ) received a stable dose of quetiapine IR $(400,600$, or $800 \mathrm{mg} / \mathrm{d})$ for the 4 -week run-in period. Patients who remained stable were then randomized to continue receiving the same dose of quetiapine IR ( $n=166$ ) or to switch to the same total daily dose of quetiapine XR $(n=331)$. There was no crosstitration period, and the switch was achieved in a single day. Analysis of the proportion of patients who discontinued due to lack of efficacy, or whose PANSS total score increased by $\geq 20 \%$ from randomization, demonstrated noninferiority of quetiapine XR compared with quetiapine IR for the per-protocol population. The results of secondary efficacy

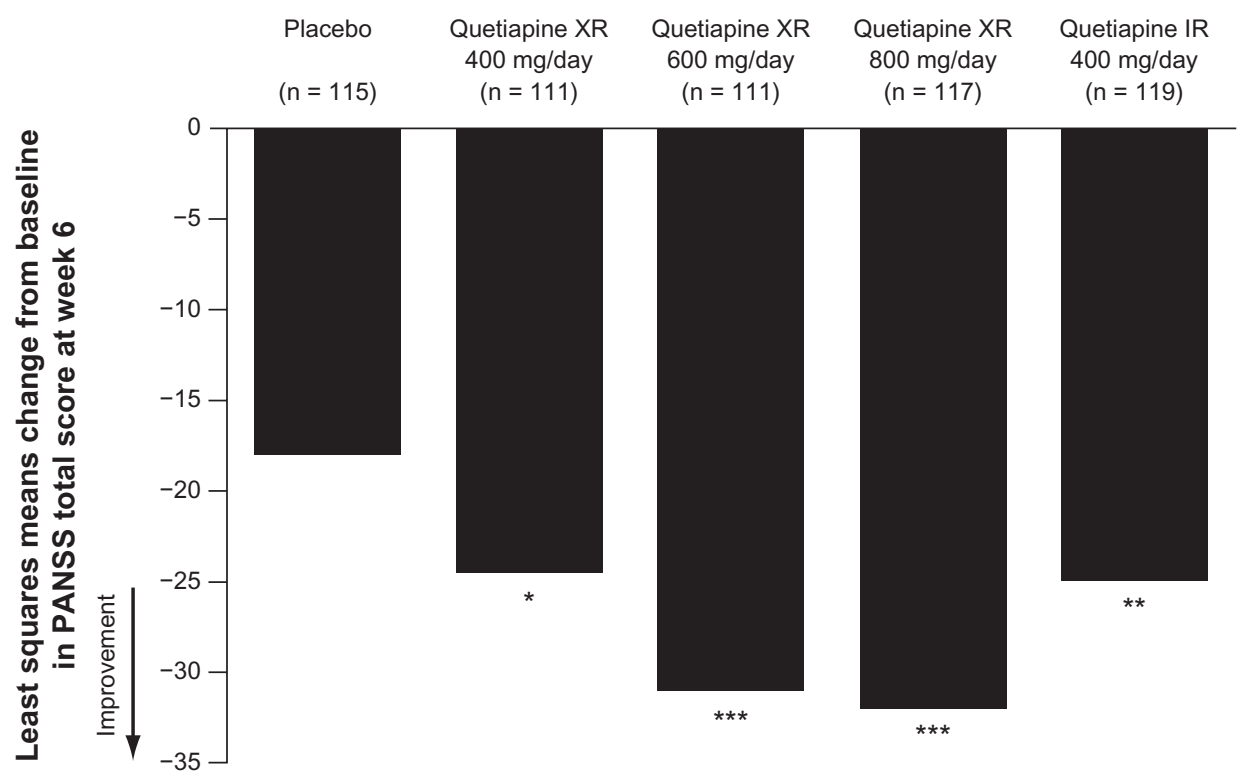

Figure 3 Change in PANSS total score from baseline to week 6 (MITT, LOCF).

Notes: $* P<0.05$; ** $P<0.01$ I; $* * P<0.001$ versus placebo.

Kahn RS, Schulz SC, Palazov VD, et al. Efficacy and tolerability of once-daily extended release quetiapine fumarate in acute schizophrenia: a randomized, double-blind, placebocontrolled study. J Clin Psychiatry. 2007;68(6):832-842. ${ }^{64}$ Copyright @ 2007 Physicians Postgraduate Press. Reprinted by permission.

Abbreviations: IR, immediate release; LOCF, last observation carried forward; MITT, modified intention-to-treat; PANSS, Positive and Negative Syndrome Scale; $\mathrm{XR}$, extended release. 
variables (including mean change in PANSS total score and proportion of patients with a CGI-I score $\leq 4$ at study end) were similar for quetiapine IR and XR, demonstrating that efficacy was maintained following the switch.

A further 12-week, open-label study (D1444C00147) investigated the potential for clinical benefit of switching to quetiapine XR from conventional or atypical antipsychotic therapy amongst in- or outpatients $(n=477)$ with schizophrenia experiencing suboptimal efficacy or tolerability with their existing treatment. ${ }^{63}$ Switching to quetiapine XR was achieved during a 4-day cross-titration period, during which the dosage of current treatment was reduced to zero by day 4 , and patients received $300 \mathrm{mg}$ quetiapine XR on the evening of day 1, $600 \mathrm{mg}$ on day 2, and were then flexibly dosed (400-800 mg/d) from day 3 onwards. The primary endpoint was the percentage of patients achieving clinical benefit, defined as an improvement in CGI-Clinical Benefit score at week 12. A significant percentage of patients (62.8\%) experienced a clinical benefit after switching to quetiapine XR; subgroup analysis showed that clinical benefit was experienced by $59.8 \%$ of patients switching due to insufficient efficacy and $68.6 \%$ of patients switching due to insufficient tolerability (Figure 4). ${ }^{63}$ Improvements in the efficacy measures CGI-S (not significant), CGI-I, and PANSS total scores (both significant) were recorded following switching to quetiapine XR. ${ }^{63}$

\section{Relapse prevention}

As schizophrenia is a chronic condition, it is critical that new treatments maintain efficacy and are well tolerated over

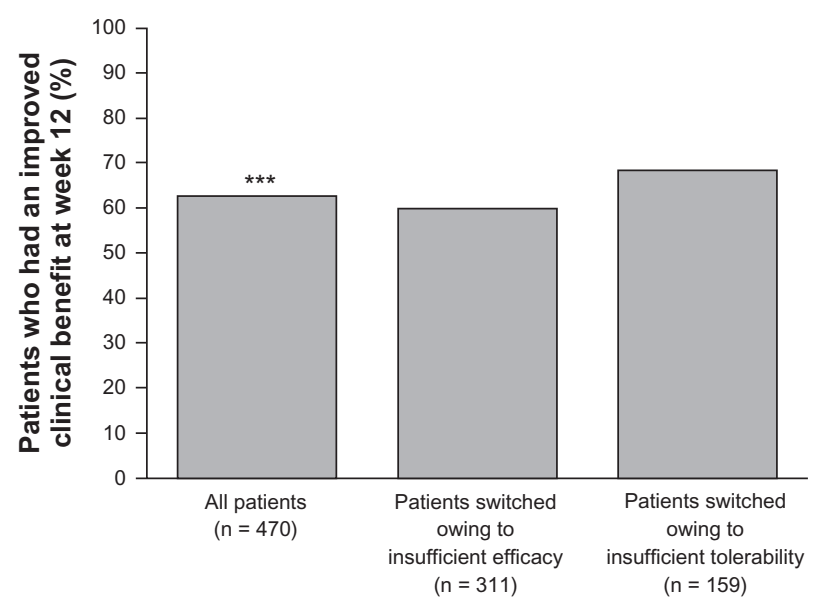

Figure 4 Percentage of patients achieving clinical benefit after switching to quetiapine $X R$ (ITT population).

Note: $* * * P<0.00$ I based on null hypothesis that $\leq 50 \%$ of patients would achieve an improvement.

Reproduced with kind permission. ${ }^{63}$ Ganesan S, Agambaram V, Randeree F, Eggens I, Huizar K, Meulien D. Switching from other antipsychotics to once-daily extended release quetiapine fumarate in patients with schizophrenia. Curr Med Res Opin. 2008;24(I):2I-32. Abbreviations: ITT, intention-to-treat; $X R$, extended release. the long term. Furthermore, prevention of relapse remains a main objective of antipsychotic treatment and one that is often not met. ${ }^{69}$

A long-term, randomized, double-blind, placebocontrolled study (D1444C00004) investigated the effectiveness of quetiapine XR at preventing relapse in patients with schizophrenia. ${ }^{31}$ Clinically stable patients $(n=327)$ were switched from their current antipsychotic to open-label, flexible-dose quetiapine XR (400-800 mg/d) in a 4-day cross-titration period, which was followed by a 16 -week stabilization phase. Those patients who were clinically stable at the end of the open-label phase were randomized to continue receiving flexible-dose quetiapine XR (400-800 mg/d) or placebo. Treatment was planned to last for 1 year, or until relapse. The study was terminated early after a pre-planned interim analysis showed that significantly more patients receiving placebo were suffering relapse compared with patients receiving quetiapine XR (Figure 5). ${ }^{31}$ The rate of relapse in the quetiapine XR group was low, and consequently it was not possible to calculate a median time to relapse. In the intention-to-treat population, the risk of relapse was reduced by $87 \%$ (hazard ratio $0.13 ; P<0.0001$ ) for patients who received quetiapine XR compared with placebo, and the estimated time at which $80 \%$ of patients remained relapse-free was 6.3 months for quetiapine XR compared with 1.2 months for placebo.

Consensus-based criteria for definition of symptomatic remission in schizophrenia were proposed in $2005 .^{70}$ The working group defined symptomatic remission as a state in which patients have experienced an improvement in core signs and symptoms to the extent that any remaining symptomatology is of such low intensity that it no longer interferes significantly with behavior. Specific core symptoms were selected to map the three dimensions of psychopathology and the five criteria for schizophrenia specified in DSM-IV. Remission was defined by the working group as having a severity score of mild or less for the core symptoms rated in one of the following scales: PANSS (item scores $\leq 3$ ); Brief Psychiatric Rating Scale (item scores $\leq 3$ ); Scale for Assessment of Positive Symptoms and Scale for Assessment of Negative Symptoms (item scores $\leq 2$ ) for a period of at least 6 months during which symptom severity must be maintained. Cross-sectional remission is defined as a symptomatic remission at a specific timepoint and does not require fulfillment of the 6-month criteria. ${ }^{70,71}$

Using these cross-sectional remission criteria, a posthoc analysis of the results of the previously described relapse prevention study ${ }^{31}$ was conducted. Following the 


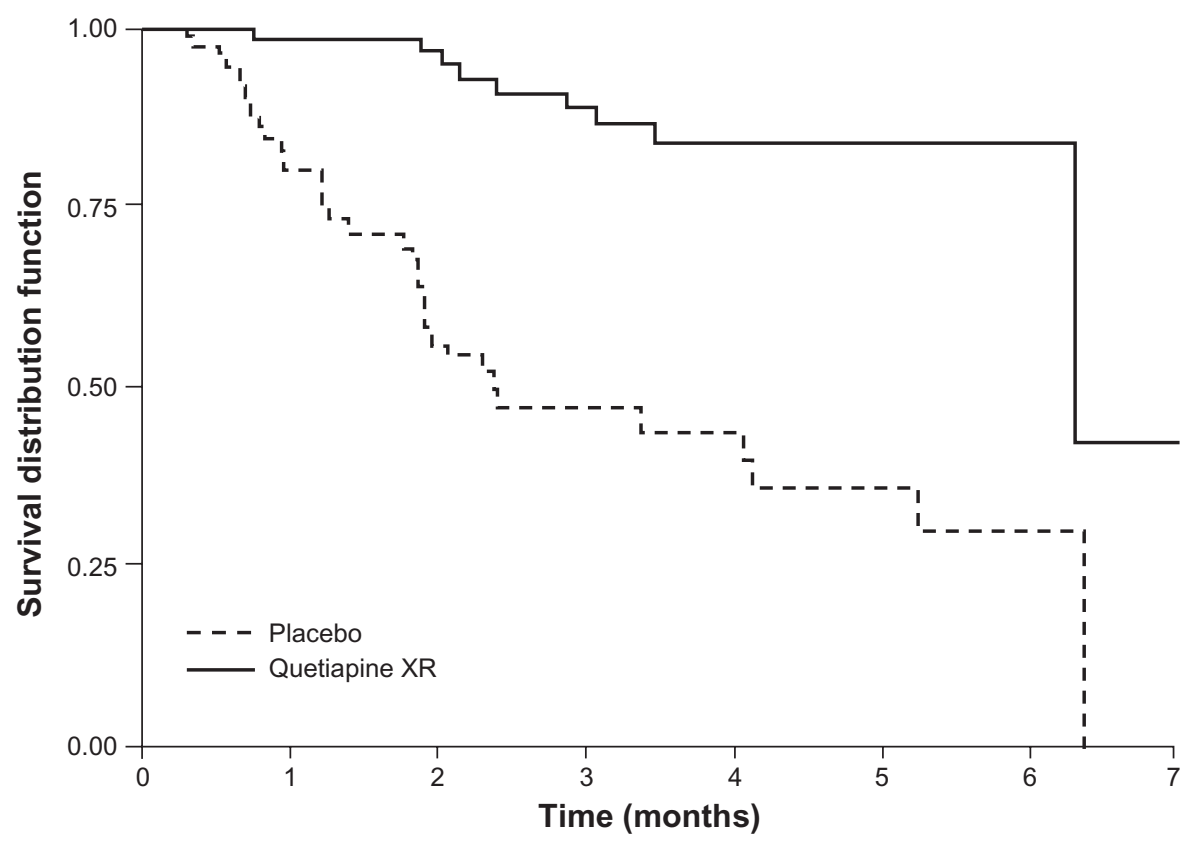

Figure 5 Proportion of patients remaining relapse-free (survival distribution function) over time with quetiapine XR or placebo in patients with schizophrenia (interim ITT population). The final steps after 6 months in the Kaplan-Meier curves are due to a late relapse of a single patient on quetiapine XR at a time when only 2 patients were at risk and to a late relapse of a single patient in the placebo group at a time when no other patient receiving placebo was at risk. Thus, after 6 months' exposure, Kaplan-Meier curves depend on single events and do not give reliable estimates of the percentage of relapse-free patients.

Peuskens J et al. Prevention of schizophrenia relapse with extended release quetiapine fumarate dosed once daily: a randomized, placebo-controlled trial in clinically stable patients. Psychiatry (Edgemont). 2007;4(I I):34-50. ${ }^{31}$ Reproduced with permission from Psychiatry (Edgemont).

Abbreviations: ITT, intention-to-treat; $X R$, extended release.

open-label phase (16-weeks quetiapine XR 400-800 mg/d), at the point of randomization into the flexible dosing phase, $96.6 \%$ of patients who had been in cross-sectional remission at enrolment were still in cross-sectional remission; furthermore, $76.6 \%$ of patients not in cross-sectional remission at enrolment were in cross-sectional remission at randomization. ${ }^{72}$ Analysis of those patients with sustained remission (patients who fulfilled remission criteria at randomization and all previous visits), showed that placebo was associated with a significantly shorter time to loss of remission compared with quetiapine XR.

\section{Safety and tolerability Quetiapine XR: overview of tolerability}

In a pooled analysis of the previously described acute studies (D1444C00132, D1444C00133, and 5077IL/0041), the incidences of AEs were similar in all three treatment groups: quetiapine XR 69.5\%, quetiapine IR $72.5 \%$, and placebo $61.4 \%$. The rates of serious AEs were low, with the highest incidence (6.1\%) occurring in the quetiapine IR $800 \mathrm{mg} / \mathrm{d}$ group and the lowest (1.1\%) occurring in the quetiapine IR $300 \mathrm{mg} / \mathrm{d}$ group; the incidence of serious AEs in the quetiapine IR, quetiapine XR, and placebo groups was $3.9 \%, 4.4 \%$, and $4.4 \%$, respectively. ${ }^{73}$
The profile of common AEs from this pooled analysis is shown in Table $3^{73}$ and was comparable in the quetiapine XR and quetiapine IR groups. The most common AEs occurring with quetiapine $\mathrm{XR}$ in these acute studies were sedation, dry mouth, somnolence, dizziness, and headache. ${ }^{73}$

In a long-term, randomized study of quetiapine XR in clinically stable patients with schizophrenia (D1444C00004, described above), a total of $49.8 \%$ of patients experienced AEs in the stabilization phase when all patients were treated with open-label quetiapine XR. In the double-blind randomized phase of the study, a comparable percentage of patients reported AEs in the quetiapine XR (31.9\%) and placebo (40.8\%) groups, of which $18.1 \%$ and $21.4 \%$, respectively, were considered treatment related. ${ }^{31}$ The majority of AEs reported throughout the study were mild to moderate in severity, and there were only two serious AEs in the study, both in placebo-treated patients (one death due to suicide and one moderate "peritonsillar abscess"). Furthermore, there were low levels of withdrawals due to AEs during the randomized phase, with one patient withdrawing from each of the quetiapine XR and placebo groups.

\section{Rapid dose initiation}

A post-hoc analysis of pooled data from two acute studies (D1444C00132 and D1444C00133, described above) 


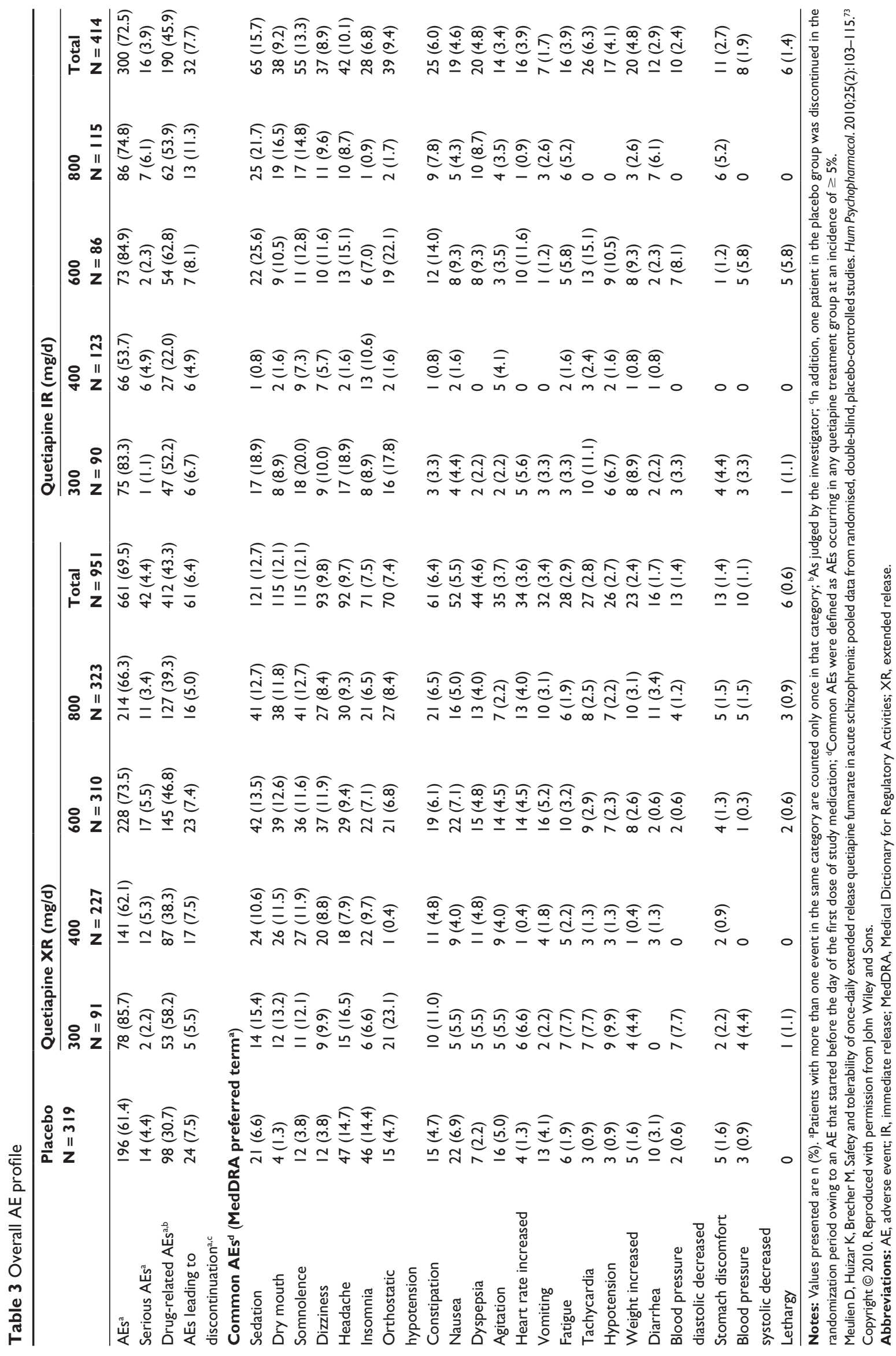


investigated the tolerability of quetiapine XR during rapid dose initiation (in these studies target doses of quetiapine XR were reached by day 2 [400 and $600 \mathrm{mg} / \mathrm{d}]$ and day $3[800 \mathrm{mg} / \mathrm{d}]) .{ }^{73}$ During the first week of treatment, the incidence of AEs was similar in the quetiapine XR (43\%) and quetiapine IR (42\%) groups, compared with $32 \%$ in the placebo group. The most commonly reported AEs in this period were somnolence, sedation, dry mouth, and dizziness in the quetiapine XR and quetiapine IR groups. The incidence of serious AEs was low in all treatment groups (1.2\% quetiapine XR, $1.3 \%$ quetiapine IR, $0.4 \%$ placebo). A total of 14 patients discontinued from the study during the first week; $10(1.5 \%)$ in the quetiapine XR groups, and two in the quetiapine IR $(0.8 \%)$ and placebo $(0.9 \%)$ groups.

Orthostatic hypotension, dizziness, and syncope are of specific concern during rapid titration of quetiapine. ${ }^{74}$ In the post-hoc analysis, the incidence of these events was low during the first week of treatment, supporting rapid initiation. $^{73}$

\section{Somnolence}

The incidence of AEs potentially associated with somnolence in short-term trials of quetiapine XR was consistent with the known safety profile for quetiapine IR: quetiapine XR, 25.0\%; quetiapine IR, 29.5\%; and placebo, 10.3\%. Events generally occurred early in treatment (median time to onset: quetiapine XR, 3.0 days; quetiapine IR, 2.0 days; placebo, 4.0 days) and were mild in intensity. ${ }^{73}$ Similarly, in the longterm study, ${ }^{31}$ the majority of AEs potentially associated with somnolence occurred during the first 2 weeks after enrolment. Overall, $19 \%$ of patients experienced somnolence during the 16-week open-label phase, when all patients were receiving quetiapine XR, and 14.4\% experienced this AE during the first 14 days. The incidence of somnolence was reduced at randomization (2.1\%), following 16-weeks of quetiapine XR $400-800 \mathrm{mg} / \mathrm{d}$, and during the randomized phase two patients receiving placebo (1.9\%) and none receiving quetiapine XR reported somnolence.

\section{EPS}

In an analysis of pooled data from three acute studies, the incidences of AEs potentially associated with EPSs were: quetiapine XR, 7.5\%; quetiapine IR, 7.7\%; and placebo $4.7 \%{ }^{73}$ The most common EPS-associated AEs were tremor, akathisia, and restlessness; no individual AE occurred with a frequency $>3 \%$ in either the quetiapine XR or quetiapine IR group. The majority of AEs related to EPSs were of mild or moderate severity.
In a long-term study, the incidence and severity of EPSs were assessed using the Simpson-Angus Scale (SAS) and Barnes Akathisia Rating Scale (BARS), monitoring of anticholinergic medication use, and AE reporting. Mean change in SAS and BARS scores from baseline to the end of treatment were -0.08 and -0.02 , respectively, in the quetiapine XR groups and -0.25 and -0.01 , respectively, in the placebo group. Anticholinergic use was low throughout, with no indication of an increase in use. ${ }^{31}$

\section{Prolactin}

Prolactin levels decreased in all treatment groups during acute studies; the mean decrease observed with quetiapine XR $(-12.96 \mathrm{ng} / \mathrm{mL})$ was comparable with both quetiapine IR $(-13.33 \mathrm{ng} / \mathrm{mL})$ and placebo $(-13.69 \mathrm{ng} / \mathrm{mL}) .{ }^{73}$ The incidence of AEs potentially associated with prolactin was also similar across the study groups.

\section{Weight and metabolic effects}

Pooled data from the three acute studies showed a mean weight gain of $1.77 \mathrm{~kg}$ in the quetiapine XR group, $2.19 \mathrm{~kg}$ in the quetiapine IR group, and $0.26 \mathrm{~kg}$ in the placebo group; there was no apparent dose-response relationship. ${ }^{73}$ A greater percentage of patients in the quetiapine $\mathrm{XR}$ and quetiapine IR groups reported a weight increase $\geq 7 \%$ compared with the placebo group (13.7\%, 19.5\%, and 6.7\%, respectively). ${ }^{73}$

During the stabilization phase of the long-term study (16 weeks), patients experienced a mean weight increase of $0.89 \mathrm{~kg}$, and $8.1 \%$ of patients experienced a weight increase $\geq 7 \%$. Following randomization, patients in the quetiapine XR group experienced a further mean weight gain of $0.46 \mathrm{~kg}$, while those receiving placebo recorded a mean decrease of $-0.68 \mathrm{~kg}$. Weight increase $\geq 7 \%$ from randomization to study end (mean duration 120 days) occurred in $5.4 \%$ of patients receiving quetiapine $\mathrm{XR}$ and $1.0 \%$ of patients receiving placebo. Over the course of the study patients receiving quetiapine XR experienced a mean weight gain of $1.06 \mathrm{~kg} .{ }^{31}$

In the acute studies, mean changes from randomization in fasting glucose levels were $+0.12,+0.27$, and $-0.01 \mathrm{mmol} / \mathrm{L}$ in the quetiapine XR, quetiapine IR, and placebo groups, respectively. ${ }^{73}$ A clinically important shift in fasting glucose to $\geq 7 \mathrm{mmol} / \mathrm{L}$ was experienced by $8.7 \%, 6.7 \%$, and $5.9 \%$ of patients in the quetiapine XR, quetiapine IR, and placebo groups, respectively. ${ }^{73}$ In the long-term study, mean change from randomization in fasting glucose levels (quetiapine XR, $+0.34 \mathrm{mmol} / \mathrm{L}$; placebo, $+0.19 \mathrm{mmol} / \mathrm{L}$ ) was similar to that seen in the short-term studies (quetiapine XR difference 
versus placebo: +0.15 and $+0.13 \mathrm{mmol} / \mathrm{L}$, respectively), with no meaningful difference between treatment groups. During the stabilization phase, mean fasting glucose levels increased by $0.05 \mathrm{mmol} / \mathrm{L}$; following randomization levels increased by $0.34 \mathrm{mmol} / \mathrm{L}$ in the quetiapine XR group and $0.19 \mathrm{mmol} / \mathrm{L}$ in the placebo group. Clinically significant shifts (to $\geq 7 \mathrm{mmol} / \mathrm{L}$ ) from baseline to end of treatment were recorded in $4.1 \%$ of patients receiving quetiapine XR and $8.0 \%$ of patients receiving placebo. ${ }^{31}$

Analysis of pooled data from acute studies quantified changes from randomization in fasting lipid parameters among the quetiapine $\mathrm{XR}$, quetiapine IR, and placebo cohorts, respectively $(+0.06,+0.15$, and $-0.06 \mathrm{mmol} / \mathrm{L}$ in lowdensity lipoprotein [LDL]; $-0.01,0.00$, and $-0.02 \mathrm{mmol} / \mathrm{L}$ in high-density lipoprotein [HDL]; and $+0.17,+0.38$, and $-0.11 \mathrm{mmol} / \mathrm{L}$ in triglycerides). ${ }^{73}$

Long-term respective changes from randomization in fasting lipid parameters among quetiapine XR- and placebo-treated patients were -0.01 and $-0.28 \mathrm{mmol} / \mathrm{L}$ (LDL), +0.01 and +0.06 $\mathrm{mmol} / \mathrm{L}$ (HDL), and -0.03 and $-0.23 \mathrm{mmol} / \mathrm{L}$ (triglycerides). ${ }^{31}$ Collectively, these data suggest that short- and long-term treatment with quetiapine $\mathrm{XR}$ does not lead to clinically meaningful changes in fasting lipid parameters.

\section{Switching}

The safety data from the switching study, which investigated the feasibility of switching from quetiapine IR to quetiapine XR at equivalent doses, indicated that the switch was not associated with any compromise in tolerability. Similar AE profiles were seen in patients who switched to quetiapine XR and those who remained on quetiapine IR; $38.7 \%$ and $35.5 \%$ of patients in the quetiapine XR and quetiapine IR groups, respectively, reported AEs. Slight increases in the incidence of some AEs were observed with quetiapine XR; however, the differences were small and may have been attributable to chance. The mean weight change was $-0.02 \mathrm{~kg}$ for quetiapine $\mathrm{XR}$ and $0.30 \mathrm{~kg}$ for quetiapine IR; weight increase $\geq 7 \%$ occurred in $1.5 \%$ of patients receiving quetiapine XR and $2.4 \%$ of patients receiving quetiapine IR. The two treatment groups were also comparable with regard to the recorded changes in laboratory values, which were small and similar in both groups. ${ }^{66}$

In patients who switched from their current medication, including conventional and atypical antipsychotics, quetiapine XR was generally well tolerated. The majority of AEs were mild to moderate in intensity, and the incidence of serious AEs and AEs leading to discontinuation was low: $4.4 \%$ and $8.0 \%$, respectively. The percentage of patients experiencing an AE was slightly higher in patients who switched due to insufficient tolerability $(75.3 \%)$ compared with patients who switched due to insufficient efficacy (68.6\%). The AE profile and effect on vital signs and laboratory data were generally consistent with other studies of quetiapine XR. For all patients, the mean change in bodyweight was $1.0 \mathrm{~kg}$; for those who switched from their previous antipsychotic due to weight gain, baseline bodyweight was higher and patients lost a mean weight of $1.6 \mathrm{~kg} .{ }^{63}$ In addition, in the long-term relapse prevention study, ${ }^{31}$ in which switching was achieved during a 4-day cross-titration period, the rate of withdrawal was low, providing supporting evidence that patients can be switched from their previous medication with little difficulty.

\section{Tolerability of quetiapine IR versus XR: sedation}

A randomized, double-blind, crossover study in healthy adult volunteers (D1443C00033) has been conducted to investigate the time course and intensity of sedation during dose initiation of quetiapine XR and quetiapine IR. ${ }^{49}$ The self-reported level of sedation was recorded using a visual analog scale. At 1 hour on day 1 (primary endpoint), quetiapine XR was associated with a significantly reduced intensity of sedation compared with quetiapine IR. The level of sedation was lower with quetiapine XR for the first 7 hours post dosing, after which levels of sedation were comparable with both formulations. ${ }^{49}$

\section{Patient-reported outcomes}

In addition to efficacy and tolerability data, the previously described trial by Ganesan et al, in which switching from other antipsychotics to quetiapine XR was evaluated, also assessed patient-reported outcomes through recording of Personal Evaluation of Transitions in Treatment (PETiT) scores (a self-administered patient questionnaire comprising 30 questions relating to perceived well being, adherence to treatment, tolerability, and satisfaction). ${ }^{63}$ At the end of the 12-week study, there was a significant improvement in PETiT total score in patients who switched to quetiapine XR; improvements were recorded irrespective of whether patients switched due to insufficient efficacy or tolerability.

It is important to consider the patients' opinions of their medication; therefore, future trials evaluating the use of quetiapine XR in patients with schizophrenia should incorporate patient-reported outcomes to provide further evidence for the benefits of the formulation. 


\section{Conclusion}

While treatment options for schizophrenia have increased significantly over the past decade, the management of schizophrenia continues to represent a considerable clinical challenge. There are often differences between patients in terms of the pharmacokinetics and pharmacodynamics of different drugs. Furthermore, the relative importance of genetic and physiological factors in the development of schizophrenia is different for each patient. Consequently, the efficacy and tolerability of specific antipsychotic treatments differs from patient to patient, thus necessitating the ongoing development of new treatment options. Moreover, the chronic nature of schizophrenia means that treatment is not limited to an acute period but instead must extend over a long-term maintenance period, increasing the importance of having a wide variety of treatment options available to clinicians.

The efficacy of quetiapine IR for the treatment of schizophrenia is well established. ${ }^{24-26}$ Quetiapine XR was developed to aid clinicians and patients by offering an alternative treatment option with once-daily dosing and a simplified dose titration schedule. For patients with schizophrenia, rapid symptom relief is important, and consequently the ability to reach therapeutic doses rapidly is an advantage. The XR formulation enables the therapeutic dose range to be reached by day 2 , with the highest dose of $800 \mathrm{mg} / \mathrm{d}$ achievable by day 3 of treatment.

To be considered a viable treatment option, quetiapine XR must have comparable, or superior, efficacy and tolerability compared with the IR formulation. In several short- and long-term studies, quetiapine XR has demonstrated comparable efficacy with quetiapine IR in patients with schizophrenia. ${ }^{31,64,65,68}$ Furthermore, it has been shown that switching to quetiapine XR from quetiapine IR does not lead to any loss of efficacy, and switching to quetiapine XR from a different antipsychotic, due to insufficient efficacy or tolerability, results in improved efficacy. ${ }^{63,66}$

Studies of patient adherence to treatment in several chronic conditions has shown that patients are more adherent to once-daily medications, compared with more frequently dosed formulations. ${ }^{75}$ Nonadherence to medication is associated with poorer treatment outcomes, negatively affecting remission and relapse rates, the need for rehospitalization, and the incidence of suicide attempts. ${ }^{8,76}$ Furthermore, nonadherence is associated with significantly increased health care utilization and, consequently, costs. ${ }^{77}$ The once-daily dosing schedule of quetiapine XR may help improve patient adherence to treatment, and as a result it has the potential to have a positive impact on patient outcomes and costs.

In common with many other atypical antipsychotics, quetiapine is associated with somnolence. ${ }^{78}$ The majority of instances of somnolence associated with either formulation of quetiapine appear to occur early in treatment and to be transient. In comparison with quetiapine IR, quetiapine XR has been shown to be associated with milder cases of sedation and somnolence, particularly during dose initiation. ${ }^{49}$ The intensity of sedation is greatest in the first 7 hours after dosing; therefore, the proposed once-daily evening dosing of quetiapine XR may minimize this potential side effect.

The evidence that successful treatment of schizophrenia must target nonpsychotic, as well as psychotic symptoms continues to increase. For example, the presence of depressive symptoms in patients with schizophrenia is associated with poorer treatment outcomes. In a recent large, 3-year, observational study, $39.4 \%$ of patients were considered to be depressed at enrolment (Montgomery-Åsberg Depression Rating Scale score $\geq 16$ ). When compared with nondepressed patients, this group was more likely to require relapse-related mental health services, attempt suicide, have substance-related problems, report a poorer quality of life, and have reduced adherence to medication. ${ }^{79}$ Quetiapine XR has been demonstrated to improve depressive symptoms over 6-weeks in patients with schizophrenia. ${ }^{64}$ In addition, the proven efficacy of quetiapine in bipolar depression ${ }^{30,80,81}$ and $\mathrm{MDD}^{37-39}$ together with its receptor-binding profile suggests that quetiapine may be an effective treatment for patients with schizophrenia and depressive symptoms.

A further treatment challenge in schizophrenia is relapse, which is common during the long-term treatment of schizophrenia. In one study, $25 \%$ of patients who achieved remission were estimated to relapse, with the risk of relapse continuing even after 3 years of remission..$^{82}$ Quetiapine XR has been demonstrated to be effective in the prevention of relapse in clinically stable patients with schizophrenia ${ }^{31,72}$ and thus offers a further treatment choice.

In conclusion, quetiapine $\mathrm{XR}$ represents an effective and generally well tolerated treatment for schizophrenia that is initiated rapidly and taken only once daily. The reduced dosing frequency with quetiapine XR may increase adherence to treatment and, in turn, improve long-term outcomes.

\section{Acknowledgments}

The author thanks Dr Alex Mitchell, PhD, from Complete Medical Communications, who provided medical writing support funded by AstraZeneca. 


\section{Disclosure}

The author reports no conflicts of interest in this work.

\section{References}

1. Weiden PJ, Preskorn SH, Fahnestock PA, Carpenter D, Ross R, Docherty JP. Translating the psychopharmacology of antipsychotics to individualized treatment for severe mental illness: a Roadmap. J Clin Psychiatry. 2007;68 Suppl 7:1-48.

2. Lacro JP, Dunn LB, Dolder CR, Leckband SG, Jeste DV. Prevalence of and risk factors for medication nonadherence in patients with schizophrenia: a comprehensive review of recent literature. J Clin Psychiatry. 2002;63(10):892-909.

3. Valenstein M, Ganoczy D, McCarthy JF, Myra KH, Lee TA, Blow FC. Antipsychotic adherence over time among patients receiving treatment for schizophrenia: a retrospective review. J Clin Psychiatry. 2006; 67(10):1542-1550.

4. Velligan DI, Lam F, Ereshefsky L, Miller AL. Psychopharmacology: perspectives on medication adherence and atypical antipsychotic medications. Psychiatr Serv. 2003;54(5):665-667.

5. Byerly MJ, Nakonezny PA, Lescouflair E. Antipsychotic medication adherence in schizophrenia. Psychiatr Clin North Am. 2007;30(3): 437-452.

6. Gitlin M, Nuechterlein K, Subotnik KL, et al. Clinical outcome following neuroleptic discontinuation in patients with remitted recent-onset schizophrenia. Am J Psychiatry. 2001;158(11): $1835-1842$.

7. Ascher-Svanum H, Zhu B, Faries D, Lacro JP, Dolder CR. A prospective study of risk factors for nonadherence with antipsychotic medication in the treatment of schizophrenia. J Clin Psychiatry. 2006;67(7): 1114-1123.

8. Leucht S, Heres S. Epidemiology, clinical consequences, and psychosocial treatment of nonadherence in schizophrenia. J Clin Psychiatry. 2006;67 Suppl 5:3-8.

9. Almond S, Knapp M, Francois C, Toumi M, Brugha T. Relapse in schizophrenia: costs, clinical outcomes and quality of life. $\mathrm{Br} \mathrm{J}$ Psychiatry. 2004;184:346-351.

10. Wyatt RJ. Neuroleptics and the natural course of schizophrenia. Schizophr Bull. 1991;17(2):325-351.

11. Marcus SC, Olfson M. Outpatient antipsychotic treatment and inpatient costs of schizophrenia. Schizophr Bull. 2008;34(1):173-180.

12. Fleischhacker WW, Hofer A, Hummer M. Managing Schizophrenia: the compliance challenge. Current Medicine Group; 2007.

13. Hudson TJ, Owen RR, Thrush CR, et al. A pilot study of barriers to medication adherence in schizophrenia. J Clin Psychiatry. 2004;65(2): 211-216.

14. Masand PS, Narasimhan M. Improving adherence to antipsychotic pharmacotherapy. Curr Clin Pharmacol. 2006;1(1):47-56.

15. Jonsdottir H, Friis S, Horne R, Pettersen KI, Reikvam A, Andreassen OA. Beliefs about medications: measurement and relationship to adherence in patients with severe mental disorders. Acta Psychiatr Scand. 2009; 119(1):78-84.

16. Tandon R, Marcus R, Stock E, et al. A prospective, multicenter, randomized, parallel-group, open-label study of aripiprazole in the management of patients with schizophrenia or schizoaffective disorder in general psychiatric practice: Broad Effectiveness Trial with Aripiprazole (BETA). Schizophr Res. 2006;84(1):77-89.

17. Kikkert MJ, Schene AH, Koeter MW, et al. Medication adherence in schizophrenia: exploring patients', carers' and professionals' views. Schizophr Bull. 2006;32(4):786-794.

18. Perkins DO, Gu H, Weiden PJ, McEvoy JP, Hamer RM, Lieberman JA. Predictors of treatment discontinuation and medication nonadherence in patients recovering from a first episode of schizophrenia, schizophreniform disorder, or schizoaffective disorder: a randomized, double-blind, flexible-dose, multicenter study. J Clin Psychiatry. 2008; 69(1):106-113.
19. American Psychiatric Association. Practice guideline for the treatment of patients with schizophrenia [updated 2004]. Available from: http://www.psychiatryonline.com/pracGuide/loadGuidelinePdf. aspx?file=Schizophrenia2ePG_05-15-06. Accessed January 21, 2010.

20. National Institute of Clinical Excellence. Core interventions in the treatment and management of schizophrenia in primary and secondary care (Clinical Guideline 1) [updated 2004 Apr 12]. Available from: http://www.nice.org.uk.

21. Tandon R, Jibson MD. Extrapyramidal side effects of antipsychotic treatment: scope of problem and impact on outcome. Ann Clin Psychiatry. 2002;14(2):123-129.

22. Haddad PM, Sharma SG. Adverse effects of atypical antipsychotics: differential risk and clinical implications. CNS Drugs. 2007;21(11): 911-936.

23. De Hert M, Schreurs V, Sweers K, et al. Typical and atypical antipsychotics differentially affect long-term incidence rates of the metabolic syndrome in first-episode patients with schizophrenia: a retrospective chart review. Schizophr Res. 2008;101(1-3):295-303.

24. Arango C, Bobes J. Managing acute exacerbations of schizophrenia: focus on quetiapine. Curr Med Res Opin. 2004;20(5):619-626.

25. Buckley PF. Efficacy of quetiapine for the treatment of schizophrenia: a combined analysis of three placebo-controlled trials. Curr Med Res Opin. 2004;20(9):1357-1363.

26. Hellewell JSE, Cameron-Hands D, Cantillon M. Seroquel ${ }^{\circledR}$ : evidence for efficacy in the treatment of hostility and aggression. Schizophr Res. 1998;29:154-155.

27. Leucht S, Kissling W, Davis JM. Second-generation antipsychotics for schizophrenia: can we resolve the conflict? Psychol Med. 2009;39(10): 1591-1602.

28. Seroquel ${ }^{\circledR}$ (quetiapine fumarate) tablets - US prescribing information. [updated 2010]. Available from: http://www1.astrazeneca-us.com/pi/ seroquel.pdf. Accessed January 18, 2010.

29. AstraZeneca. Seroquel XR (quetiapine fumarate) extended release tablets - US prescribing information [updated $2011 \mathrm{Mar}$ ]. Available from: http://www1.astrazeneca-us.com/pi/seroquelxr.pdf. Accessed May 5, 2011.

30. Suppes T, Datto C, Minkwitz M, Nordenhem A, Walker C, Darko D. Effectiveness of the extended release formulation of quetiapine as monotherapy for the treatment of acute bipolar depression. J Affect Disord. 2010;121(1-2):106-115.

31. Peuskens J, Trivedi JK, Malyarov S, et al. Prevention of schizophrenia relapse with extended release quetiapine fumarate dosed once daily: a randomized placebo-controlled trial in clinically stable patients. Psychiatry (Edgemont). 2007;4(11):34-50.

32. Seroquel XR (quetiapine fumarate) Extended-Release Tablets - US prescribing information. [updated 2010]. Available from: http://www1. astrazeneca-us.com/pi/seroquelxr.pdf. Accessed April 23, 2010.

33. AstraZeneca. Seroquel XR - Summary of product characteristics [updated 2010]. Available from: http://www.medicines.ie/ medicine $/ 13032 / \mathrm{SPC} /$ Seroquel+XR+50mg $\% 2 \mathrm{c}+200 \mathrm{mg} \% 2 \mathrm{c}+300 \mathrm{mg}$ \%2c+400mg+prolonged-release+tablets/. Accessed March 5, 2010.

34. AstraZeneca. Seroquel XR and seroquel approved in europe for prevention of recurrence of bipolar disorder [updated 2009]. Available from: http://www.astrazeneca.com/media/latest-press-releases/2009/ Seroquel_Bipolar_Maint_EU?itemId=7082393. Accessed January 21, 2010.

35. El-Khalili N, Joyce M, Atkinson S, et al. Extended-release quetiapine fumarate (quetiapine XR) as adjunctive therapy in major depressive disorder (MDD) in patients with an inadequate response to ongoing antidepressant treatment: a multicentre, randomized, double-blind, placebo-controlled study. Int J Neuropsychopharmacol. 2010;13(7):917-932.

36. Bortnick B, El-Khalili N, Banov M, et al. Efficacy and tolerability of extended release quetiapine fumarate (quetiapine XR) monotherapy in major depressive disorder: A placebo-controlled, randomized study. J Affect Disord. 2011;128(1-2):83-94. 
37. Bauer M, Pretorius HW, Constant EL, Earley WR, Szamosi J, Brecher M. Extended-release quetiapine as adjunct to an antidepressant in patients with major depressive disorder: results of a randomized, placebo-controlled, double-blind study. J Clin Psychiatry. 2009;70(4): 540-549.

38. Cutler AJ, Montgomery SA, Feifel D, Lazarus A, Åström M, Brecher M. Extended release quetiapine fumarate monotherapy in major depressive disorder: a placebo- and duloxetine-controlled study. J Clin Psychiatry. 2009;70(4):526-539.

39. Weisler R, Joyce M, McGill L, Lazarus A, Szamosi J, Eriksson H. Extended release quetiapine fumarate monotherapy for major depressive disorder: results of a double-blind, randomized, placebo-controlled study. CNS Spectr. 2009;14(6):299-313.

40. Katzman MA, Brawman-Mintzer O, Reyes EB, Olausson B, Liu S, Eriksson H. Extended release quetiapine fumarate (quetiapine XR) monotherapy as maintenance treatment for generalized anxiety disorder: a long-term, randomized, placebo-controlled trial. Int Clin Psychopharmacol. 2011;26(1):11-24.

41. Merideth C, Cutler A, Neijber A, She F, Eriksson HA. Efficacy and tolerability of extended release quetiapine fumarate (quetiapine XR) monotherapy in the treatment of generalised anxiety disorder (GAD). Eur Neuropsychopharmacol. 2008;18:S499.

42. Bandelow B, Chouinard G, Bobes J, et al. Extended-release quetiapine fumarate (quetiapine XR): a once-daily monotherapy effective in generalized anxiety disorder. Data from a randomized, double-blind, placebo- and active-controlled study. Int J Neuropsychopharmacol. 2010;13:305-320.

43. Khan A, Joyce M, Atkinson S, Eggens I, Baldytcheva I, Eriksson H. A randomized, double-blind study of once-daily extended release quetiapine fumarate (quetiapine XR) monotherapy in patients with generalized anxiety disorder. J Clin Psychopharmacol. 2011;31: $418-428$

44. AstraZeneca. Seroquel XR recommended for approval in EU as an add-on treatment of major depressive disorder [updated 2010]. Available from: http://www.astrazeneca.com/media/latest-press-releases/ seroquelXR-MDD?itemId=9260911. Accessed April 23, 2010.

45. AstraZeneca. US FDA approves seroquel XR for add-on treatment of major depressive disorder [updated 2009]. Available from AstraZeneca. Accessed January 21, 2010.

46. Figueroa C, Brecher M, Hamer-Maansson JE, Winter H. Pharmacokinetic profiles of extended release quetiapine fumarate compared with quetiapine immediate release. Prog Neuropsychopharmacol Biol Psychiatry. 2009;33(2):199-204.

47. DeVane CL, Nemeroff CB. Clinical pharmacokinetics of quetiapine: an atypical antipsychotic. Clin Pharmacokinet. 2001;40(7):509-522.

48. Nemeroff CB, Kinkead B, Goldstein J. Quetiapine: preclinical studies, pharmacokinetics, drug interactions, and dosing. J Clin Psychiatry. 2002;63(Suppl 13):5-11.

49. Datto C, Berggren L, Patel J, Eriksson HA. Self-reported sedation profile of immediate-release quetiapine fumarate compared with extended-release quetiapine fumarate during dose initiation: a randomized, double-blind, crossover study in healthy adult subjects. Clin Ther. 2009;31:492-502.

50. Juckel G, Winter HR, Ståhle L, Miller F, Strid S. The pharmacokinetics of extended release quetiapine fumarate are not affected by a light meal. Poster presented at the 14th Biennial Winter Workshop on Schizophrenia and Bipolar Disorders, Montreux, Switzerland, February 3-7, 2008.

51. Goldstein JM, Christoph G, Grimm S, Liu J, Widzowski D, Brecher M. Quetiapine's antidepressant properties: direct and indirect pharmacologic actions on norepinephrine and serotonin receptors. Eur Neuropsychopharmacol. 2007;17(Suppl 4):S401.

52. Seeman P. Atypical antipsychotics: mechanism of action. Can J Psychiatry. 2002;47(1):27-38

53. Roth BL, Sheffler D, Potkin SG. Atypical antipsychotic drug actions: unitary or multiple mechanisms for 'atypicality'? Clin Neurosci Res. 2003;3:108-117.
54. Kapur S, Seeman P. Antipsychotic agents differ in how fast they come off the dopamine $\mathrm{D}_{2}$ receptors. Implications for atypical antipsychotic action. J Psychiatry Neurosci. 2000;25(2):161-166.

55. Nyberg S, Zukin S. PET-measured occupancy of the $\mathrm{D}_{2}$ receptor: a comparison of quetiapine fumarate immediate- and extended-release formulations in healthy subjects. Poster presented at the 48th Annual Meeting of the American College of Neuropsychopharmacology, Hollywood, Florida, USA, December 6-10, 2009.

56. Nyberg S, Widzowski D. Translational pharmacology of quetiapine and norquetiapine: preclinical findings support multifunctional psychotropic properties. Eur Psychiatry. 2010;25:1446.

57. Nyberg S, Takano A, Grimm S, et al. PET-measured D2, 5-HT2, and norepinephrine transporter (NET) occupancy by quetiapine and N-desalkyl-quetiapine in non-human primates. Eur Neuropsychopharmacol. 2007;17(Supp1 4):S254-S255.

58. Jensen NH, Rodriguiz RM, Caron MG, Wetsel WC, Rothman RB, Roth BL. N-desalkylquetiapine, a potent norepinephrine reuptake inhibitor and partial 5-HT $\mathrm{H}_{(1 \mathrm{~A})}$ agonist, as a putative mediator of quetiapine's antidepressant activity. Neuropsychopharmacology. 2008; 33(10):2303-2312.

59. Mamo DC, Uchida H, Vitcu I, et al. Quetiapine extended-release versus immediate-release formulation: a positron emission tomography study. J Clin Psychiatry. 2008;69(1):81-86.

60. Pillai A, Terry AV Jr, Mahadik SP. Differential effects of long-term treatment with typical and atypical antipsychotics on NGF and BDNF levels in rat striatum and hippocampus. Schizophr Res. 2006;82(1):95-106.

61. Fumagalli F, Molteni R, Bedogni F, et al. Quetiapine regulates FGF-2 and BDNF expression in the hippocampus of animals treated with MK-801. NeuroReport. 2004;15(13):2109-2112.

62. Xu H, Qing H, Lu W, Keegan D, Richardson JS, Li X-M. NR72: quetiapine attenuates the immobilization-induced decrease of BDNF in rat hippocampus. Poster presented at the American Psychiatric Association, Philadelphia, Pennsylvania, USA, May 18-23, 2002.

63. Ganesan S, Agambaram V, Randeree F, Eggens I, Huizar K, Meulien D. Switching from other antipsychotics to once-daily extended release quetiapine fumarate in patients with schizophrenia. Curr Med Res Opin. 2008;24(1):21-32.

64. Kahn RS, Schulz SC, Palazov VD, et al. Efficacy and tolerability of once-daily extended release quetiapine fumarate in acute schizophrenia: a randomized, double-blind, placebo-controlled study. J Clin Psychiatry. 2007;68(6):832-842.

65. Lindenmayer JP, Brown D, Liu S, Brecher M, Meulien D. The efficacy and tolerability of once-daily extended release quetiapine fumarate in hospitalized patients with acute schizophrenia: a 6-week randomized, double-blind, placebo-controlled study. Psychopharmacol Bull. 2008; 41(3):11-35.

66. Moller HJ, Johnson S, Mateva T, et al. Evaluation of the feasibility of switching from immediate release quetiapine to extended release quetiapine fumarate in stable outpatients with schizophrenia. Int Clin Psychopharmacol. 2008;23(2):95-105.

67. Cutler AJ, Tran-Johnson T, Kalali A, Astrom M, Brecher M, Meulien D A failed 6-week, randomized, double-blind, placebo-controlled study of once-daily extended release quetiapine fumarate in patients with acute schizophrenia: lessons learned. Psychopharmacol Bull. 2010; 43(4):37-69.

68. Kalali A, Schulz SC, Kahn RS, et al. Effectiveness of once-daily extended release quetiapine fumarate (quetiapine XR) for excitability, hostility and aggression in schizophrenia. Poster 4002 presented at the 161st Annual Meeting of the American Psychiatric Association, Washington, DC, USA, May 3-8, 2008.

69. Leucht S, Barnes TR, Kissling W, Engel RR, Correll C, Kane JM. Relapse prevention in schizophrenia with new-generation antipsychotics: a systematic review and exploratory meta-analysis of randomized, controlled trials. Am J Psychiatry. 2003;160(7):1209-1222.

70. Andreasen NC, Carpenter WT Jr, Kane JM, Lasser RA, Marder SR, Weinberger DR. Remission in schizophrenia: proposed criteria and rationale for consensus. Am J Psychiatry. 2005;162(3):441-449. 
71. Leucht $\mathrm{S}$, Lasser R. The concepts of remission and recovery in schizophrenia. Pharmacopsychiatry. 2006;39(5):161-170.

72. Peuskens J, Trivedi JK, Brecher M, Miller F. Long-term symptomatic remission of schizophrenia with once-daily extended release quetiapine fumarate: post-hoc analysis of data from a randomized withdrawal, placebo-controlled study. Int Clin Psychopharmacol. 2010;25: 183-187.

73. Meulien D, Huizar K, Brecher M. Safety and tolerability of once-daily extended release quetiapine fumarate in acute schizophrenia: pooled data from randomised, double-blind, placebo-controlled studies. Hum Psychopharmacol. 2010;25(2):103-115.

74. Boidi G, Ferro M. Rapid dose initiation of quetiapine for the treatment of acute schizophrenia and schizoaffective disorder: a randomised, multicentre, parallel-group, open study. Hum Psychopharmacol. 2007; 22(5):299-306.

75. Saini SD, Schoenfeld P, Kaulback K, Dubinsky MC. Effect of medication dosing frequency on adherence in chronic diseases. Am J Manag Care. 2009;15(6):e22-e33.

76. Ascher-Svanum H, Faries DE, Zhu B, Ernst FR, Swartz MS, Swanson JW. Medication adherence and long-term functional outcomes in the treatment of schizophrenia in usual care. J Clin Psychiatry. 2006; 67(3):453-460.
77. Knapp M, King D, Pugner K, Lapuerta P. Non-adherence to antipsychotic medication regimens: associations with resource use and costs. $\mathrm{Br} J$ Psychiatry. 2004;184:509-516.

78. Gao K, Ganocy SJ, Gajwani P, Muzina DJ, Kemp DE, Calabrese JR. A review of sensitivity and tolerability of antipsychotics in patients with bipolar disorder or schizophrenia: focus on somnolence. $J$ Clin Psychiatry. 2008;69(2):302-309.

79. Conley RR, Ascher-Svanum H, Zhu B, Faries DE, Kinon BJ. The burden of depressive symptoms in the long-term treatment of patients with schizophrenia. Schizophr Res. 2007;90(1-3):186-197.

80. McElroy SL, Weisler RH, Chang W, et al. A double-blind, placebocontrolled study of quetiapine and paroxetine as monotherapy in adults with bipolar depression (EMBOLDEN II). J Clin Psychiatry. 2010; 71(2):163-174.

81. Young AH, McElroy SL, Bauer M, et al. A double-blind, placebocontrolled study of quetiapine and lithium monotherapy in adults in the acute phase of bipolar depression (EMBOLDEN I). J Clin Psychiatry. 2010;71(2):150-162.

82. Haro JM, Novick D, Suarez D, Alonso J, Lepine JP, Ratcliffe M. Remission and relapse in the outpatient care of schizophrenia: three-year results from the schizophrenia outpatient health outcomes study. J Clin Psychopharmacol. 2006;26(6):571-578.
Neuropsychiatric Disease and Treatment

\section{Publish your work in this journal}

Neuropsychiatric Disease and Treatment is an international, peerreviewed journal of clinical therapeutics and pharmacology focusing on concise rapid reporting of clinical or pre-clinical studies on a range of neuropsychiatric and neurological disorders. This journal is indexed on PubMed Central, the 'PsycINFO' database and CAS, and is the official

\section{Dovepress}

journal of The International Neuropsychiatric Association (INA). The manuscript management system is completely online and includes a very quick and fair peer-review system, which is all easy to use. Visit $\mathrm{http} / / / \mathrm{www}$.dovepress.com/testimonials.php to read real quotes from published authors. 